\title{
TRAS LAS HUELLAS DEL PÍCARO EN LA CULTURA VENEZOLANA. RAÍCES Y DERIVACIONES
}

\section{IN THE FOOTSTEPS OF THE CONVIVIAL TRICKSTER IN CULTURE. ROOTS AND DERIVATIONS}

\author{
Revista Trama \\ Volumen 10, número 1 \\ Enero - Junio 2021 \\ Páginas 132-165 \\ ISSN: 1659-343X \\ https://revistas.tec.ac.cr/trama
}

Elena Sosnowski ${ }^{1}$ / Karen Cronick ${ }^{2}$

Fecha de recepción: 21 de marzo, 2020.

Fecha de aprobación: 19 de junio, 2021.

Sosnowski, E. y Cronick, K. (2021). Tras las huellas del pícaro en la cultura. Raíces y sus derivaciones. Trama, Revista de ciencias sociales y humanidades, Volumen 10, (1), Enero-Junio, págs. 132-165.

DOI: https://doi.org/10.18845/tramarcsh.v10i1.5786

1. Doctoranda Ciencias Sociales y Humanidades. Universidad Simón Bolívar. Caracas, Venezuela.

Correo electrónico: esosnows@gmail.com ORCID: https://orcid.org/0000-0002-3382-2938

2. Ph.D. Profesora Titular (jubilada), Posgrado en Psicología Social. Universidad Central de Venezuela. Caracas, Venezuela. 


\section{RESUMEN}

El trabajo revisa y cuestiona la figura del "pícaro" en Venezuela, que la literatura reconoce con alguna frecuencia en la idiosincrasia latinoamericana y caribeña. Con la ayuda del concepto de "personalidad modal" de Ruth Benedict, antropóloga, de la corriente del configuracionismo cultural, el objetivo es describir esta "personalidad" tal como ha sido abordada por variados autores, particularmente Axel Capriles, psicólogo, y desarrollar para ella una contextualización histórica y sociológica. Para eso se revisan autores provenientes del campo de la antropología/etnopsicoanálisis (Samuel Hurtado), la sociología (Alberto Gruson), la psiquiatría (José Luis Vethencourt) y la psicología (Alejandro Moreno), quienes desde el enfoque del psicoanálisis, fundamentaron aspectos de la sociedad venezolana, que se relacionan con esta personalidad. El método utilizado es una selección documental intencional que desglosa el tema del pícaro venezolano desde ángulos disciplinarios diversos y que arroja luz sobre la pregunta sobre esta figura y su funcionalidad en la sociedad, con una revisión crítica de los argumentos de los autores, entre los que se incluyen el matricentrismo, la matrisocialidad y la indefensión.

Revisamos los significados por la posible evolución del término a lo largo de la historia y para una posible segmentación interpretativa del significado de pícaro, por su importancia simbólica en la construcción de cultura y para promover una apertura a la problematización de los rasgos de identidad que no operan en favor de la cohesión social.

Palabras clave: pícaro, cultura, matricentrismo, matrisocialidad, Venezuela

\section{ABSTRACT}

The work reviews and questions the figure of the "trickster/rogue" in Venezuela, recognized in the literature with some frequency in the Latin American and Caribbean idiosyncrasy. With the help of Ruth Benedict's concept of "modal personality", an anthropologist from the cultural configurationism school, the authors examine this phenomenon. The purpose of this paper is to describe this "personality" as it has been approached by different authors, specially Axel Capriles, psychologist, and to develop its historical and sociological contextualization. For this, authors from the field of anthropology/ ethnopsychoanalysis (Samuel Hurtado), sociology (Alberto Gruson), psychiatry (José Luis Vethencourt) and psychology (Alejandro Moreno) are reviewed. They have examined aspects of Venezuelan society, which are related to this personality. The method used is an intentional documentary selection that breaks down the subject of the Venezuelan "trickster/rogue" from different disciplinary angles and sheds light on the question about this figure and its functionality in society. We include a critical review of the authors' arguments, such as matricentering, matrisociality and helplessness.

We attempt a critical review of the possible evolution of the meaning of the "trickster/ rogue" throughout history and search for new interpretations of its meaning, due to its symbolic importance in the construction of culture. We hope to promote a new problematization of its possible negative identity traits.

Key words: trickster, culture, matricentering, matrisociality, Venezuela 


\section{INTRODUCCIÓN}

En este artículo analizamos la figura del "pícaro"3 en Venezuela. Se trata de una configuración social y antropológica que podríamos llamar "personalidad" o "manera de vivir y convivir" que es frecuente en la región del Caribe, sobre todo en la costa norte de América del Sur. Hemos abordado esta configuración con la ayuda del concepto de "personalidad modal" de Ruth Benedict, tal como ella lo elaboró en su libro "Patterns of Culture". El pícaro es una figura reconocible en el país, una idiosincrasia frecuente en la población, aunque claro, no representa a todos sus habitantes. Para Capriles (2010) constituye la expresión de un arquetipo, como disposición presente en todo ser humano, que se activa, se desactiva o también puede convertirse temporalmente en un dominante cultural.

El objetivo es describir esta "personalidad" tal como ha sido estudiada por variados autores y desarrollar para ella una contextualización histórica y sociológica. Diversas investigaciones de autores con énfasis en la antropología, la sociología y la psicología, como Capriles (2008), Hurtado (2014), Gruson (2004), McClelland (1976), Zapata (1996) y otros, fundamentaron aspectos de la sociedad venezolana, relacionados con esta personalidad. Una personalidad que también se describe como la de un sobreviviente, una individualidad valiente e ingeniosa que ha podido superar guerras, sublevaciones, penurias y pérdidas.

El pícaro queda como un rostro llamativo y divertido, pero al mismo tiempo, preocupante en la sociología y la psicología del Caribe. Es importante revisarlo, porque su influencia puede sentirse, al punto de haber motivado variadas reflexiones, la mayoría de las cuales revisamos en este artículo.

Nuestro trabajo es un desglose del tema del pícaro venezolano; hemos identificado diferentes autores con heterogéneos puntos de vista que arrojan luz sobre esta figura, desde ángulos disciplinarios diversos. Sobre sus apreciaciones hemos elaborado nuestras propias observaciones, y las hemos colocado en el texto junto a los argumentos de los analistas elegidos. En esto consiste el método de este artículo: se trata de una revisión de la literatura actual sobre un tema psicosocial y antropológico que ha sido poco examinado con la seriedad que merece.

3. A pesar del uso de "pícaro" en masculino, el sentido del término es inclusivo para la mujer, aunque los protagonistas de las historias de "pícaros" son masculinos y así también se los asocia generalmente en la cotidianidad. 
En la primera sección consideramos lasideas decultura, personalidad, leyenda y norma. En la segunda nos referimos a la noción específica del pícaro en la literatura venezolana, y consideramos las consecuencias de esta manera de actuar y sentir. En la tercera esbozamos algunas posibles causas de este fenómeno, incluyendo el matricentrismo y la indefensión. Terminamos con unas breves reflexiones finales. 


\section{LA CULTURA}

No existe una única definición para la palabra "cultura". En 1952, Alfred Kroeber y Clyde Kluckhohn afirmaron que habían encontrado 164 definiciones, solo en la literatura profesional de la antropología cultural (Menand, 2019). La definición de cultura de la Real Academia Española (2020) es: "el conjunto de conocimientos que permite a alguien desarrollar su juicio crítico / conjunto de modos de vida y costumbres, conocimientos y grado de desarrollo artístico, científico, industrial, en una época, grupo social". Esta definición incorpora las diferentes acepciones generales, como aquellas que tienen que ver con el acervo de conocimientos sobre la literatura y la música que un individuo podría tener. La Declaración Universal de la UNESCO sobre Diversidad Cultural, reafirma que la cultura,

... debe ser considerada el conjunto de los rasgos distintivos espirituales y materiales, intelectuales y afectivos que caracterizan a una sociedad o a un grupo social y que abarca, además de las artes y las letras, los modos de vida, las maneras de vivir juntos, los sistemas de valores, las tradiciones y las creencias (UNESCO, 2001).

Benedict (1934) la definió no solo en términos del conjunto de creencias y rasgos, sino también como un patrón: dijo que la cultura es una configuración de características particulares como conocimientos, creencias y valores individuales. Además, tiene formas o patrones porque constituye una entidad coherente e integrada.

Es evidente que "cultura" es un concepto colectivo. Ha sido abordado desde puntos de vista diferentes por los conocidos antropólogos culturales como Franz Boas y Margaret Mead, por los sociólogos como Émile Durkheim -conciencia colectiva- (Durkheim, 1893) y por los psicólogos sociales como Moscovici -representaciones sociales- (Moscovici, 1961/1979). 


\section{La cultura y la personalidad}

Ruth Benedict, Margaret Mead y Ralph Linton son tres antropólogos culturales que abordan el problema de los lazos entre la cultura y la personalidad en los grupos culturales. Sus enfoques incluyen:

1) la relación existente entre cultura y naturaleza humana, 2) las personalidades típicas que existen en el marco de una cultura y 3) los procesos y mecanismos de incorporación de la cultura por parte de los individuos pertenecientes a ésta (Restrepo, 2016, p. 25).

Se basan en gran parte en la importancia de la lingüística y la tradición oral. Sus intereses radican en las relaciones entre la cultura y el individuo, o más precisamente, entre los patrones o instituciones culturales y la existencia de ciertos tipos de personas "modales" en una cultura determinada. Benedict, Mead y Linton fueron influenciados por el psicoanálisis freudiano, y deseaban encontrar no solo los rasgos o patrones culturales particulares, sino también unos modelos de personalidad que caracterizaban a dicha cultura (Restrepo, 2016).

Por su parte Emile Durkheim habla de la "conciencia colectiva" que sería: "La totalidad de creencias y sentimientos comunes a los miembros típicos de una sociedad" (Cole, 2019, párrafo 3). Son las influencias sociales e institucionales que forman a los individuos y fundan creencias compartidas que influyen en su conducta.

\subsection{Las leyendas y su influencia}

Las leyendas forman parte de esta "totalidad" y desde tiempos homéricos señalan no solo la historia fundante de los pueblos, sino también su sentido de identidad. La llíada marcó para los griegos su uniformidad como pueblo -en comparación con los egipcios, persas y otros grupos circundantes-. La "mesa redonda" del Camelot del Rey Arturo de Gran Bretaña, definió el ideal de "buen gobierno" y la meta de la igualdad política. Los símbolos y los significados de las leyendas marcan a las culturas por muchos siglos.

\section{Leyendas en Venezuela}

Hay muchas leyendas venezolanas, algunas de las cuales se refieren a la historia compartida, sobre todo con referencia a la guerra de liberación de España. Uslar Pietri recogió muchas de ellas en su libro "Lanzas Coloradas" (1931). 
Pero hay otras leyendas que se formaron entre los habitantes de las haciendas de Los Llanos, en los días antes de la manumisión de los esclavos, y luego en las condiciones inseguras y empobrecidas de los cafetaleros, hatos de Aragua y la zona de Los Andes del Siglo XIX del tiempo de las Guerras Federales. La mayoría tienen que ver con la posibilidad de encontrar espíritus malignos en los caminos oscuros de la noche. Estos espíritus son seres que se enloquecieron y cometieron horrendos crímenes; luego se convirtieron en monstruos que atacan a personas desprevenidas. Ejemplos son: la Sayona y el Silbón. La Loca Luz Caraballo es una mujer que perdió sus hijos en la Guerras de Independencia y sigue apareciendo llorando por los caminos. Otras leyendas cuentan mitos de figuras elogiadas, como María Lionza o María de la Onza quien ahora es considerada una diosa popular; sobre ella se ha erigida una religión chamánica muy arraigada en el país.

\section{El conejo}

Según Campbell (1959/1991) en "Las Máscaras de Dios", (The masks of God) algunos personajes de leyenda que provienen del Paleolítico, siguen activos en la literatura moderna. De los tiempos prehistóricos de los primeros asentamientos agrícolas de Mesopotamia y Grecia hay cuentos chamánicos que se han preservado.

Campbell (1959/1991) sugiere una fuente común para los mitos, tanto sobre el origen del mundo como el de la humanidad. Según esta fuente, elcreadordel mundoseencarna en lafiguradelchamán/curandero/ mediador en la época paleolítica de los cazadores y recolectores. Pero luego en los tiempos clásicos de los reinos mesopotámicos, el chamán individual se convirtió en uno de los múltiples sacerdotes que formaban parte de un templo asociado con la estructura de poder local. Señala Campbell que cuando las culturas agrarias se asentaron y se organizaron, los hechiceros libres tenían que ser sometidos: fueron "puestos en fila, de uniforme, se les concedía un lugar en una estructura litúrgica de un todo más amplio" (Campbell, p. 275), es decir, vestidos de sacerdotes, era algo más grande que el sortilegio particular.

Ya para las civilizaciones agrarias los hechiceros representaban un pasado que había que superar: fueron caracterizados como gamberros incivilizados y sin ley. Del mismo modo en Grecia los titanes fueron conquistados por los dioses; los gnomos y los gigantes se personificaban como amenazantes y execrables. Paralelamente, los espíritus chamánicos devenían dioses que aparecían en pinturas y estatuas en centros de oráculos. Entre los personajes de los cuentos chamánicos hay un conejo 
embustero que proviene de una tradición mítica que tiene que ver con el creador del universo. Nos cuenta Campbell que esta liebre tiene una historia compleja en fábulas arcaicas donde aparece como hacedor y benefactor de la humanidad. Es interesante que Prometeo, el titán de la mitología griega, también fuera un tramposo/benefactor, y si en realidad descendió del chamán/conejo prehistórico, ya en tiempos griegos aparecía humanizado (Cronick, 2018).

Algunas tribus africanas preservaron estas historias y con la llegada de los esclavos a las Américas, y tras su subsecuente conversión al cristianismo, las leyendas originales se diluyeron en cuentos para entretener a los convidados de las reuniones sociales. De sus orígenes transcendentales, el conejo tramposo se ha convertido en el personaje principal en las leyendas para niños. En Venezuela lo conocemos como "Tío Conejo" (Uslar Pietri, 1987, Capriles, 2008) o "Tío Tigre y Tío Conejo", publicado por Antonio Arráiz en 1945, todos con personajes ya conocidos y que formaban parte de la cultura popular, mientras que en los Estados Unidos tiene el nombre de "Brear Rabbit" (Harris, 2007).

En Venezuela, el Tío Conejo no es sólo una leyenda. Es un ícono de la venezolanidad. Aparentemente se trata de una serie de cuentos para niños, pero en el fondo es un referente social:

Él representa la eterna lucha entre el débil y el fuerte; entre la inteligencia y la fuerza bruta. Pero, Tío Conejo no es ni un fenómeno venezolano ni americano. Sus raíces están profundamente arraigadas en los pícaros africanos... Las luchas de los esclavos africanos para sobrevivir física y culturalmente están de alguna manera contenidas en los relatos del travieso conejo, cuyas bromas proporcionaban alegría e inspiración para los esclavos, quienes veían en el pícaro la posibilidad de que su situación cambiara o al menos se hiciera llevadera, si tan solo actuaran inteligentemente, como el conejo de las historias (Lezama, s/f).

De este modo, la picardía del Tío Conejo rebasa un simple irrespeto a las leyes y las normas dominantes de la sociedad. Por extensión "la picardía criolla", un rastro cultural típico del Caribe, viene a ser una voz manumisora, sin llegar a ser sistemáticamente liberadora. Es decir, esta sagacidad y astucia, no se traduce en formas de autogestión social y política. Es una alegría insubordinada, anárquica e individual. 
ElTío Conejo remite inexorablemente a la idea de la viveza criolla de toda la zona del Caribe sur. Regresaremos a esta figura cuando hablemos particularmente de la picardía venezolana. Por ahora consideraremos esta picardía en relación a la personalidad modal en el país. 


\section{CULTURA Y NORMA EN VENEZUELA}

La idea de la personalidad modal viene de los antropólogos Mead y Benedict, a quienes nos referimos anteriormente. Se trata de un estilo de personalidad que se encuentra con frecuencia entre la gente de un país, y que es reconocido en gran medida como una particularidad del carácter nacional. Franz Boas, el mentor de Mead y Benedict, dijo: "No todas las culturas son controladas por una personalidad dominante, pero pareciera que mientras más conocemos las motivaciones culturales que activan el comportamiento de un individuo, más encontraremos que ciertas normativas sobre la emoción, ciertos ideales de conducta, [que] prevalecen que dan cuenta de lo que no entendemos desde el punto de vista de nuestra propia civilización" (Boas, 1934, p. xvi).

Algunas características de la personalidad venezolana, y sobre las que suele haber consenso, válidas también para el pícaro, es que nada representa un obstáculo que no pueda resolverse; es alegre y vivaz, y cualquier crisis la abrocha con optimismo personal, hasta en las situaciones más complejas, evitando la queja sobre lo cotidiano. Es sociable por naturaleza, busca convertir los inconvenientes en situaciones jocosas para reír juntos y revertir los momentos críticos a instantes de alegre intimidad. Dos palabras muy presentes en el lenguaje coloquial nacional son pilas y quedado, la primera para calificar un estado de ánimo, despierto y con reacciones inmediatas y la segunda para describir críticamente lo contrario. Son estas palabras las que describen la actitud del venezolano para enfrentarse a los problemas cotidianos, donde su naturaleza le indica cómo esquivar los límites que se le imponen. Hurtado (2014) describe esta personalidad así: "creativo, simpático, tiene sentido del humor, es hábil, inteligente, hasta piensa rápido utilizando su picardía y su bravilabia" (p. 40). En sus estudios asocia esta personalidad, lo que los antropólogos llaman la personalidad modal, con formas de crianza que remiten a una anomia en el ambiente familiar, una matrisocialidad, un enfoque que en este particular aspecto comparte con Vethencourt (1974) y Moreno (2008a, b y c). Está claro que otros modos coexisten, aunque sean opuestos y forman parte de los extremos de la personalidad modal que estamos examinando.

A continuación, consideramos otras perspectivas relacionadas con el pícaro. 


\section{Trabajos sobre idiosincrasia, motivaciones y personalidad del venezolano}

Rial (1986, c. p. Romero, 1999), realizó un estudio sobre las motivaciones del venezolano, donde se ubicó el poder como primer factor de motivación. Reporta los resultados de un trabajo que realizó en la Sloan School of Management del Instituto de Tecnología de Massachusetts, con una muestra de 100 gerentes venezolanos y 29 de estadounidenses, del sector privado y la administración pública, donde predominó esta motivación al poder. Romero, afirma que "un perfil motivacional de alto poder, moderada afiliación y bajo logro, es una constante cultural y vale tanto para el trabajador no calificado como para el gerente con maestría universitaria" (Romero, 1999 p. 153).

Romero explica dos posibles vertientes del poder: a) un poder socializado y b) un poder personalizado. Para Romero (1999), el poder socializado se manifiesta en el apoyo al grupo, esto para McClelland (1989) se manifiesta con pensamientos de poder para tener impacto en beneficio de otros, donde la motivación al poder para el propio individuo o para influenciar y "volcarlo" en la sociedad, se constituye en una escala progresiva de madurez del individuo. Entonces, el poder socializado es el que podría tener un político honesto, mientras que el poder personalizado se manifiesta como una búsqueda permanente de derrotar a los otros, suma 0 , si tú ganas yo pierdo, y viceversa, como el del explotador/depredador, como el político que opera solo para su propio beneficio,

Estas investigaciones se hicieron con posterioridad a las de David Berlew, María Eugenia Curiel y David McClelland, quienes habían investigado en Venezuela sobre la frecuencia de las tres necesidades/ motivaciones que McClelland describe en su teoría, que son la motivación al logro, la afiliación interpersonal y el poder sobre los demás. El poder se ubicó en la primera línea de motivaciones del sujeto, y la afiliación y el logro quedaron en un distante segundo y tercer lugar (McClelland, 1976 c. p. Capriles, 1996)

McClelland (1976) enfatizaba en la motivación al logro tanto como rasgo cultural como también una característica personal, y lo consideraba básico para que un país o grupo tuviera éxito. Se trata de la motivación para resolver problemas y alcanzar las metas propuestas, a diferencia de la motivación al poder. 
Este tema del poder se vincula con lo que desarrolla Capriles (2008) en "La picardía del venezolano o el triunfo de Tío Conejo" donde expone una psicología picaresca del venezolano, que vive en los límites de la transgresión, el rechazo a las normas generales y las leyes abstractas, una "viveza criolla", por un conflicto con el poder, usa la viveza y la astucia para escabullirse de él. La relación particular con el poder y la norma, sobresale también en la investigación de Zapata (1996), sobre los valores del venezolano.

\section{La norma en Zapata}

Esta investigación contiene la descripción de los valores en las relaciones del individuo con los demás, los objetivos sociales y vitales, los valores en la familia, la ética, la moral y la religiosidad, y examina sus actitudes hacia el trabajo y la política. Se realizó a lo largo del año 1994, con encuestas en los hogares de 20.000 habitantes mayores de dieciocho años, en 199 puntos muestrales, 62 centros poblados de 39 zonas metropolitanas o ciudades importantes de las regiones Capital, Central, Llanos, Centro Occidental, Zulia, Andes y Oriente. El estudio, además del valor que contiene en el foco de las preguntas y su rigor metodológico, tiene un valor histórico para quienes investigan los factores psicosociales que expone el trabajo y la evolución de los valores en el tiempo. Para nuestro análisis, seleccionamos de la investigación aquellos elementos que se relacionan con las normas. Para el conjunto de los venezolanos encuestados en 1994, los valores importantes eran: a) la libertad (54 \%); b) que se prefería a la igualdad (33\%) y c) el $13 \%$ no optaba por lo uno ni lo otro.

Para Zapata (1996) sin libertad no hay persona moral, sin libertad política, no hay persona política. "La automatización de los individuos y la alienación de la esfera social creemos que puede borrar los horizontes de la misma libertad" (p. 51). Pero, es la igualdad la base de una normativa de relaciones democráticas entre las personas. Por esto Zapata observa que por un lado el venezolano pide libertad para la iniciativa y el despliegue personal, pero al mismo tiempo pide mano dura con los demás, y resalta, cómo junto con la demanda de autoridad, se reporta la personalidad autoritaria del venezolano en las dos escalas que fueron utilizadas: 
..."autoridad", "disciplina", "líderes fuertes", "mano dura"... referidas siempre al externo y concretamente al gobierno, como controlador del entorno social. Algo así como una petición de: "denme libertad a mí, pero me controlan todo lo que está fuera de mí", "libre yo, pero me controlan a los demás", libertad personal, pero mano fuerte social, económica, etc. (Zapata, 1996, p. 61).

Así, los venezolanos encuestados esperan por el Estado para la aplicación de las normas mientras que para ellos quieren libertad. Zapata (1996) lo interpreta como un egoísmo, más que un individualismo, asociándolo al hecho de que el venezolano,

...tiene que convivir con una marcada conciencia de necesidades fundamentales insatisfechas y una creciente incertidumbre para su satisfacción desde la perspectiva individual, la demanda de autoridad encuentra fácil ubicación, se constituye en la guía más segura para la satisfacción de esas necesidades, no únicamente por la vía de un gobierno proveedor, sino de una autoridad que controle a los que abusan (Zapata, 1996).

Para el $61 \%$ de los encuestados de Zapata (1996) la vida familiar da mucha satisfacción y el conflicto de padres e hijos no está presente, porque el rigor familiar es menor que en épocas pasadas y hay menos cosas contra las que rebelarse. El primer lugar de los temas de conversación familiar lo ocupan temas morales, lo que está bien y lo que está mal. Entre las normas que se transmiten en la familia, ocupan en primer lugar los valores instrumentales, necesarios para conseguir unos valores terminales $u$ objetivos que se tienen en la vida. Los valores instrumentales se refieren a las maneras de ser y de comportarse para conseguir los valores finales. Esto implica valores internalizados en el proceso de socialización. Los que se desea que se internalicen y lo que uno valora en la vida, esto es importante porque indica lo que los venezolanos se esfuerzan en inculcar a las generaciones en formación.

La encuesta partió de doce cualidades que se intenta transmitir a los niños: ser honesto en la vida, aplicado en los estudios, respetar a los demás, tener sentido de responsabilidad, tener buenos modales, ser obedientes, tener fe en Dios, ser religioso, perseverante, constante, independiente, dar valor al dinero y al ahorro, tener hábitos de trabajo y espíritu de sacrificio. 
Al organizar los resultados de las normas que resulta importante transmitir a los niños y asociarlas a tipos de virtudes, las virtudes/ cualidades relativas a los hábitos de trabajo, la perseverancia y la constancia, quedaron rezagadas, a pesar de que parecían destacarse previamente como cualidades que se valora en las personas. Es decir, se valora una cosa, pero se enseña otra.

Tabla 1. Esquema de normas que se consideran importantes para transmitir a los niños

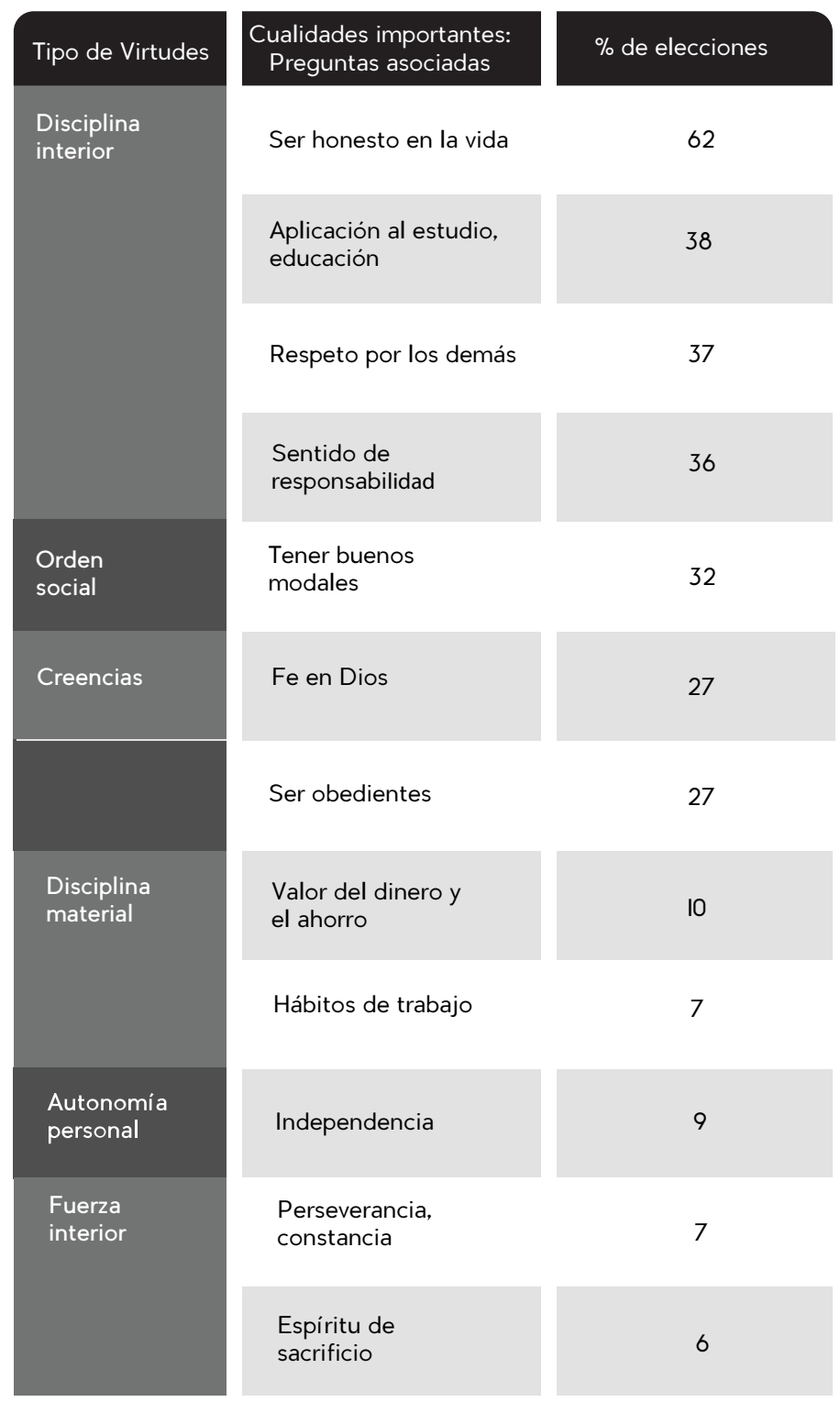

Fuente: Los valores del venezolano. Zapata (1996, p. 73). 
En la encuesta también fueron analizadas las ideas sobre lo que es bueno y lo que es malo. Un $46 \%$ respondió que considera que existen normas claras sobre lo que está bien y lo que está mal y que esas normas se aplican siempre, a todas las personas y en cualquier circunstancia. Mientras que otro $46 \%$ estima que nunca podrá haber normas totalmente claras sobre lo que está bien y lo que está mal, porque lo bueno y lo malo depende completamente de las circunstancias del momento. Esto último implica un relativismo de la norma con el riesgo de usar una doble moral, un criterio para uno mismo y otro para los demás. Para Zapata (1996) cómo se aplican las normas y cómo se actúa frente a la transgresión de las mismas es importante, puesto que "lo que sostiene al valor es el hábito o rutina de repetir actos; el que éstos se conviertan en virtudes dependerá de su contenido moral en relación con aquel valor final (p. 93).

En este sentido, en la encuesta de Zapata (1996) se realizaron trece preguntas que pusieron a prueba el rigor del razonamiento moral de los encuestados, desde la máxima justificación o mayor permisividad y mínima justificación o menor permisividad en relación con diversas acciones. Aparecen tres grupos: en la máxima justificación, está el divorcio, la pena de muerte y pedir comisión. Un grupo cercano, que incluye la prostitución, el aborto, colearse en fiestas, homosexualidad y evadir impuestos, con justificaciones que implican cuestionamiento moral, pero con tolerancia. El tercer grupo constituido por relaciones sexuales con menores, comprar algo que ha sido robado, consumo de drogas, suicidio, manejar bajo efectos del alcohol, con la mínima justificación. No hay diferencias en la valoración que justifica estas acciones entre aquellos para quienes está claro lo que está bien y está mal y aquellos que lo hacen depender de las circunstancias, dejando ver que esas acciones tienen un orden moral, ético, ciudadano autónomo de raíz social. Sin embargo, en el nivel familiar de la libertad personal y del control personal de la propia vida, entra una mayor tolerancia, en contraste con los ámbitos públicos.

Como resultado del estudio, es el tema moral y la ambigüedad entre la opción objetiva y relativa de las normas, lo que está entre las cosas que más inquieta (Zapata, 1996).

A partir del trabajo concluye Aveledo (1996) sobre la necesaria formación para la libertad y la responsabilidad como deber de la sociedad democrática, desde el liderazgo con la ley, la prédica y el ejemplo; y como cierre, el análisis de Piñango (1996) sobre la paradoja del venezolano que llama la atención: expresa su preferencia por la libertad, pero anhela un gobierno fuerte que controle a la población. 


\section{La picardía del venezolano en Capriles}

Hemos revisado la figura del conejo en las leyendas paleolíticas y hemos hecho una breve referencia a su puesto en la cultura de Venezuela. Luego analizamos los valores del venezolano, donde sobresalen algunos elementos que se encuentran en el pícaro. Ahora los veremos más de cerca bajo la óptica de Capriles, y en referencia directa a la idea de la "viveza criolla".

Capriles (2008) expone una psicología picaresca del venezolano, describe la "viveza criolla", característica resaltada en otros pueblos latinoamericanos. El título del libro hace referencia a los cuentos de tradición oral con dos personajes que oponen la fuerza de uno contra la astucia del otro, típico de la simbología que cuestiona la dominación, en la tradición latinoamericana con figuras arquetípicas que simbolizan virtudes y defectos humanos u oposición entre débiles y fuertes (Rodríguez-Bello y Rodríguez, 2006). Capriles manifiesta que escribió este trabajo luego de años de observación y encuestas a venezolanos en diferentes tiempos, lugares y momentos que le permitieron recoger el significado de pícaro de distintas maneras y en diversas latitudes:

...es un producto histórico, la expresión particular de un personaje general que en otras geografías aparece con mayor o menor fuerza como el embaucador, el tramposo o el engañador. Toda la cultura hispánica de la cuenca del Caribe ha sido particularmente sensible a su influjo. De allí, la resonancia emocional y el común denominador de ciertos rasgos que compartimos con muchos pueblos antillanos (Capriles, 2008, p. 13).

Esa figura suele denominarse como el "vivo", o el "pájaro bravo" o también el "avispado", es hábil, diestro y efusivo, se siente su presencia en el automóvil y en las colas ${ }^{4}$ para hacer trámites administrativos, con rasgos que se reproducen de manera infecciosa. La indiferencia o el desprecio por otros cánones morales que los pícaros utilizan y fingen aceptar es uno de los rasgos que comparten universalmente los personajes embaucadores míticos y picarescos, quienes, con una personalidad inconstante, pueden adoptar descaradamente posiciones opuestas de un momento a otro, "lo fundamental para el éxito no es saber, sino ser astuto y echado pa'lante" (Capriles, 2008, p. 62). 
La picardía es una disposición, conducta o atributo de carácter que podría estar presente en todas las personas, sitios y tiempos y se encuentra en todos los continentes, pero para el autor es casi un signo distintivo del venezolano que viene con capacidad de adaptación, estoicismo y astucia del débil para enfrentar la fuerza bruta y la sed de mando. Pero subraya el autor, que esta disposición a la picardía o viveza, figura entre los principales indicadores de actitudes y creencias disfuncionales para el desarrollo, junto con la desconfianza o suspicacia, ambos en la personalidad del pícaro (Capriles 2008). Capriles relaciona la economía informal con la anarquía. Esta "economía" se refiere a los revendedores que con frecuencia instalan quioscos u ocupan puestos en la acera sin permiso oficial. La falta de oportunidades económicas, junto con una enorme desigualdad social, contribuyen a prácticas como la especulación callejera de productos sin reglamentación. Este recurso por parte de los excluidos de la economía formal es común en las sociedades menos desarrolladas y no significa necesariamente un ejemplo de la personalidad modal del pícaro. Sin embargo, una vez que el pícaro se encuentra inmerso en sus negocios irregulares, el estilo del disimulado, travieso y malicioso termina expresándose:

La común subestimación de las Humanidades ha hecho pensar que las figuras picarescas de la literatura y el folclore nada tienen que decir en el análisis y la formulación de políticas públicas. ¡Grave equivocación! Ellas participan con roles estelares en el esclarecimiento de muchos problemas económicos y sociales contemporáneos: El individualismo anárquico, que como hemos visto, es una condición moldeada en buena parte por el arquetipo del pícaro, es un importante determinante psicológico de la economía informal, un sector que ocupa aproximadamente la mitad de los trabajadores del país. Diversos estudios sociológicos sobre los valores sociales y aspiraciones de los venezolanos destacan que una de las principales "cosas por las que vale la pena esforzarse" es la independencia, tener su propio negocio, trabajar por su cuenta, sin jefes, sin horarios, con normas y programación propia, sin nadie que los mande (Capriles, 2008, pág. 154). 
Ubica al pícaro en una psicología de la supervivencia, un sujeto abierto a la incertidumbre y la sorpresa, hábil para vivir en el presente sin preocuparse por el futuro y no dispuesto a las postergaciones. No profundiza en sus experiencias con compromiso y dedicación "para nutrir sus relaciones, prefiere la emoción de los encuentros furtivos, el inmediatismo, la inconstancia" (Capriles 2008, p. 122), evade la responsabilidad personal, pendiente de la gratificación inmediata, de vivencias utilitarias.

El arquetipo del pícaro se activa especialmente frente a la innovación y la transición. El contrario del pícaro "aparece como una disposición referida a la virtud, los límites y el orden, la dignidad, la seriedad y la moderación, los valores, la rigidez, la pureza, la autoridad, el honor y la firmeza" (Capriles, 2008, p. 123). Para Capriles, la personalidad [modal] del venezolano rechaza particularmente la norma y gusta de lo ilegal, el autor lo llama "individualismo anárquico": "la costumbre de solucionar los conflictos por vías legales e institucionales no es parte de nuestra cultura subjetiva"(p. 138) y refiere una investigación que concluye que "la noción de que reglas generales y abstractas puedan ser imparcialmente aplicadas por una institución impersonal es vista generalmente con desconfianza" (Blank, 1973 c. p. Capriles, 2008).

El autor interpreta que es el uso abusivo de las leyes y la justicia para aumentar el poder del gobierno y perseguir a la disidencia, frente a un inmenso Estado que no cumple a cabalidad con sus funciones pero sí es capaz de limitar las libertades de los ciudadanos en su vida individual y económica, que la sociedad venezolana aprendió a evadir los controles burocráticos oficiales y a actuar fuera de las normas y dice "la viveza no es un antojo, sino una necesidad" (Capriles, 2008, p. 19) por la corrupción administrativa y la precariedad de la vida de mucha gente en los barrios, en niveles de supervivencia.

Se trata de un alma caribe orgullosa de ser la excepción de la regla y tener rutas de acceso privadas para obtener lo que se quiere, donde estatutos y normas no son valores ni instrumentos funcionales. Rodeos, trampas, conexiones periféricas solventan las necesidades, en lugar de acatar ordenanzas y leyes al pie de la letra: "Un particularismo sobre el universalismo como regla para sopesar y evaluar el curso de nuestras acciones" (Capriles, 2008, pág. 143) un tipo de cultura que propició lo individual por encima de la organización social con base en principios y normas universales: 
Es una emoción mucho más íntima, una tonalidad afectiva ligada al rechazo visceral a la ley como guion para modelar su existencia. Es un lenguaje implícito, un sistema de distinción que asciende socialmente al vivo, un código de ética colectivo que valoriza lo ilegal, pero no necesariamente lo delictivo. Se enfoca hacia una especie de narrativa, hacia formas retóricas del habla ordinaria, hacia una apreciación visceral por la que las acciones que evaden la norma colectiva gozan de buena reputación y son juzgadas favorablemente. Es la sensación de libertad que da vivir en los límites de la transgresión, el espacio vital que se abre cuando las reglas fijas no alcanzan a ceñirnos. Tiene que ver, además, con cierta liviandad llena de humor y gracia" ( $p$. 144).

Capriles (2008) describe específicamente al pícaro asociado al personalismo político latinoamericano. En la psicología política criolla está "el espíritu indómito que no se somete a instituciones y leyes" (p. 144) que no logró llegar a la comprensión del poder propia de la modernidad democrática, como una cualidad ligada al cargo y la institucionalidad; sino que somos personalistas, al hacer depender el mando de la persona que lo ejerce y de la empatía con el gobernante, despreciando las relaciones sociales normadas por principios generales que le dan legitimidad al poder.

Para Capriles (2008) la razón está en la historia, es por el ánimo con el que llegó el conquistador a América, de desgaste de los ideales colectivos y donde se encontró con un mundo nuevo que estaba lleno de sorpresas, donde no había fronteras, límites, un orden central que le impusiera normas, leyes o códigos y señales. Sin todo eso, debía ingeniarse para sobrevivir.

Es importante recalcar que no estamos hablando de una personalidad para el conjunto de los venezolanos, es importante para esto, recordar la noción de la personalidad modal de Benedict y otros antropólogos culturales en donde el predominio de un tipo de personalidad llama la atención por su frecuencia y colorido. Es evidente que en cualquier cultura coexisten muchos tipos de personalidades, y Venezuela no es una excepción. 


\section{Causas estructurales: el matricentrismo y la matrisocialidad}

Las culturas no existen en el vacío. Descansan sobre estructuras sociológicas y razones históricas que las moldean en una relación recíproca de construcción social. En la primera sección hablamos de la estructura colonial y pos-colonial de esclavitud que daba a las víctimas pocos recursos de acción. La posibilidad de establecer y construir una familia les era negada a los esclavos. Además, después de la lucha de independencia, hubo mucha destrucción.

Torres (2009) cita a Simón Bolívar en 1814: “Una devastación universal ejercida con el último rigor ha hecho desaparecer del suelo de Venezuela la obra de tres siglos de cultura, de ilustración y de industria. Todo ha sido anonadado" (p. 15). Se calcula una mortandad de 262.000 personas en estos años y en la Guerra Federal (1858-1864) se calculan 60.000 muertos (Salamanca, 2015). En ese entonces la población del país era de 850.000 personas (Figueroa Brito, 1967); en consecuencia, estamos hablando de la pérdida de casi $10 \%$ de los habitantes en un periodo de dos generaciones. Como se puede apreciar, en los primeros años de la República, la presión poblacional era enorme, y el sentimiento de quebranto experimentado por los supervivientes en estos tiempos solo puede imaginarse.

Estas tragedias afectan a las sociedades. La muerte de los combatientes dejó a Venezuela casi sin hombres, y las mujeres tenían que subsistir como podían. No es de sorprenderse que en el país se desarrollara algo así como un "matriarcado". 
Las colectividades portan una cultura, pero su composición social no es homogénea, los grupos y subculturas generan tensiones internas dentro de la colectividad, con sus propias realidades (Gruson, 2004) y las normas que se requieren para mantenerlas, que Hurtado (2014), caracteriza como fruto de la matrisocialidad venezolana. Moreno $(2008 a, b, c)$ analizó en este sentido la familia popular venezolana matricentrada, como estructura portadora de normas. Según Vethencourt (1974) el matricentrismo, en un primer momento histórico, tiene que ver con el impacto de la colonización, donde los españoles y sus descendientes tuvieron dos o más ámbitos familiares, uno legítimo y otro ilegítimo. Las familias que se establecieron con madres autóctonas, no tenían las condiciones de herederos. Según este autor, la sociedad se fue estructurando por consanguinidad matrilineal. Para Moreno las estructuras familiares distintas a la familia de origen, tradicionalmente formado (los padres están casados y se mantienen unidos), son débiles y carecen de las condiciones necesarias para la formación adecuada de los niños.

Esta aproximación es necesario enriquecerla con la idea de las nuevas estructuras familiare ${ }^{5}$ y un creciente reconocimiento de que esa estructura de la familia no es lo que garantiza un ambiente estable y del cariño necesario para criar hijos de manera exitosa. Más bien, estamos reconociendo que factores como bienestar económico, la capacidad para relacionarse que tienen los cuidadores de los niños y su grado de formación educativa y social son factores más importantes que la identidad de los que crían a los niños.

Sin embargo, queda claro que el trauma histórico de la familia venezolana que hemos mencionado, junto con los efectos de la exclusión económica en un país de mucha desigualdad social ${ }^{6}$, tal como se refiere en el Informe Encuesta Nacional de Condiciones de Vida (UCAB/ENCOVI), afectan todavía el ambiente de crianza de muchos niños.

5. Familias nucleares, en cohabitación, unipersonales, monoparentales, reconstituida, con hijos adoptivos, homoparentales, polinucleares, extensas amplias o compuestas. Ver las descripciones de cada una en Martínez-Monteagudo, Estévez e Inglés, en Psicologia. com. 2013; 17 (6), http://hdl.handle.net/10401/6171

6. De acuerdo con el Proyecto Encovi 2019, 79,3\% de los venezolanos no pueden cubrir la canasta de alimentos, en relación con la línea de pobreza, 96\% de los hogares están en situación de pobreza y $79 \%$ en pobreza extrema. Al analizar desde el método multidimensional, que incluye además de ingresos, las variables relacionadas con empleo, educación, condiciones de la vivienda y los servicios públicos, $65 \%$ de los hogares se encuentran en situación de pobreza. Fuente: https://www.proyectoencovi.com/informeinteractivo-2019 
Debido a estas variadas razones, hubo una desorganización familiar que trajo como consecuencia la dificultad para una plena realización personal del sujeto, cuya coherencia intrapsíquica depende en buena medida de la familia nuclear, según autores como Moreno y Vethencourt, aunque hoy en día se reconozca que la composición de las familias es menos significativa que el ambiente emocional de tranquilidad y constancia, y que las influencias dañinas provienen de las traumas de pérdida y ansiedad.

Entre las consecuencias mencionadas por Vethencourt (1974) de la falta de una figura paterna permanente, está la falta de conciencia crítica para enfrentarse a la injusticia del mundo y una reducción de la solidaridad humana. Moreno (2008c), quien explica la matricentralidad como la familia estructurada alrededor del amor de la madre, donde el padre prácticamente no está presente como figura de apoyo, coincide con Vethencourt en la probable necesidad de tener dos figuras parentales, pero lo atribuye a un elemento antropológico y no a un rasgo cultural. Por esa estructura matricentrada familiar es que, según Moreno (2008a), la sociedad venezolana tiene una dificultad para unificar los pactos reales y formales de la modernidad. En la teoría freudiana el padre simboliza el super-yo y la ley y sobre él descansa la responsabilidad individual. En cambio, según Moreno, el sujeto venezolano se erige sobre la relación y la convivialidad, donde la libertad y la razón se piensan desde la relación y el amor con la madre, lo evalúa así también Lodo-Platone (2002) cuando analiza la aplicación de las normas en el hogar por parte de la madre.

Gruson (2004) señala la importancia de las formas de crianza para los portadores de una cultura, cuyos modos comunes conforman una estructura básica de personalidad, una intersubjetividad y un sentido común, con formas esperadas de enfrentarse a la realidad circundante. Esto es el producto del aprendizaje, de la socialización, de los retos existenciales que forman la personalidad y entre ellos, la superación del Edipo en la dependencia afectiva materno-filial. Cómo se trata a los niños canaliza el afecto de una forma, no reflexiva, y una censura que establecerá un superego. A esas primeras manipulaciones y disciplinas que aplican los adultos a los niños, prestan especial atención los sociólogos y antropólogos de tendencia psicoanalítica, como Hurtado (2014) y Gruson (2004), quien explica así el yo ideal: 
...es una representación de sí inconsciente, narcisista, preedípica; es un sentimiento de potencia, hasta en la negación del obstáculo y del otro en aras de la afirmación de sí, y es a la vez, imagen complaciente de cómo el yo desea ser visto e imagina que lo es. Un superyó se forma, inclusive desde el período preedípico, con la incorporación de lo que los adultos aprueban y prohíben, hasta constituirse en observador, modelo y juez del yo; es así el inductor de los sentimientos de culpabilidad y de inferioridad. El ideal del yo procede de la maduración diferenciada del yo, de la persona, en acuerdo con un ideal reflexivo que se enriquece y ensancha por el esmero en educación, religión, moral. El yo se pliega y somete al superyó por temor, se sujeta y ordena al ideal del yo por amor. Las tres instancias del yo (yo ideal, superyó, ideal del yo) conviven, naturalmente, y gobiernan unas $u$ otras secuencias de la vida personal, como lo hacen análogamente en episodios, sectores y niveles de la vida social y cultural (Gruson, 2004, pág. 20-21).

\section{La indefensión}

Para Capriles (2008) la evitación de la norma en forma de picardía es un mecanismo de resistencia pasiva, es un recurso del humor para evitar la dominación todopoderosa cuando no es posible enfrentarla, un reto encubierto y una forma de sobrevivir sin verdaderamente someterse. $Y$ atribuye la falta de internalización de la norma en la historia del pueblo venezolano a una historia de personalismo, despotismo, autoritarismo y opresión, además de violencia y dictadura que "impidió la acción e internalización de la norma como mecanismo de regulación y control socialmente útil. Nuestras vicisitudes históricas frustraron la maduración institucional y nos dejaron solos, desprotegidos e indefensos frente a la concentración y a la arbitrariedad del poder" (Capriles, 2008, pág. 149).

Similar posición tiene el intelectual Cabrujas (1995a) cuando habla de una indefensión, sin creer en una viveza en el sentido de astucia, picardía, gran destreza o una gran habilidad:

Nuestra historia niega eso, ¿cuándo fuimos vivos?, ¿qué hicimos para merecer ese calificativo? Basta ver el país, ¿dónde está la viveza de un país que despilfarró 250 mil millones de dólares en veintitantos años?, ¿cuál es la viveza de un país que se encuentra en este atolladero gigantesco, después de despilfarrar una de las más colosales fortunas que se pueda alguien imaginar? (s/p). 
Cabrujas (1995a), describe un eventollamado el "Caracazo", ocurrido el 27 de febrero de 1989, donde hubo una protesta masiva con saqueos y una violenta respuesta de parte de las fuerzas de orden. Venezuela vivió un colapso ético, una explosión que se tradujo en un saqueo que no fue revolucionario, no hubo consigna, las personas asaltaban locales en una alegría delirante, que corresponde a una ética muy particular. Para Cabrujas el venezolano imitaba el patrón presidencial, si el Estado miente, si el poder en Venezuela está formado por una cúpula de "pendencieros", ninguna ley impide entrar en una carnicería y llevar media res. No es viveza, sino un drama, un gran conflicto humano.

Cabrujas (1995a) contrapone la imagen de Bolívar, paradigma para el venezolano de lo sublime, que nadie describiría como pícaro sino como inteligente, talentoso, con genio, un ícono moral que enfrenta la vida con pasión y poder moral, a la imagen, cierta o falsa, que el venezolano se ha atribuido como pueblo. Para Cabrujas, habría que desterrar la idea de la viveza que acompaña al venezolano, porque "aquí lo que hay es un lento, dramático y desesperado esfuerzo de una sociedad por asumirse a sí misma, en un territorio y dentro de unas costumbres y unos códigos que ni le corresponden, ni la expresan y, en ocasiones, ni siquiera la sueñan" (1995a, p. s/n), porque vivir, para Cabrujas, es defenderse del Estado (Cabrujas, 1995b). 


\section{REFLEXIONES FINALES}

El concepto de la viveza criolla ni es claro, ni inequívoco, y parece pedir una deconstrucción del término para trabajar desde los diferentes significados y tonalidades, sustentado en los contextos históricos del país. Es evidente que aparece una diferenciación entre viveza, picardía y laxitud con diferentes niveles de transgresión a la norma. El pícaro que describe Capriles, podría comprenderse en Cabrujas como un embaucado por el Estado, o incluso y tal vez en ambos, negando la condición de vivo, para dejar ese atributo para quienes engañan con otra clase de peso moral, y entender al pícaro en el que elude normativas menores en el terreno de las convenciones; mas el lugar cambiante del ser humano, hace que estas fronteras sean demasiado tenues y por eso, poco justificables.

Sin embargo, Mafud, en un análisis del argentino, sí logra hacer una distinción entre el pícaro y el vivo, que operan en el campo moral de manera diferente. El pícaro en Mafud,

... siempre será un desalojado social, dentro de la sociedad siempre desciende. Para él todo avance es inútil. Su ideal es estar donde está y no descender, quedarse aferrado a lo que tiene. En cambio el vivo se cree dueño de la sociedad. Está hecha para él y sus habitantes sólo le interesan en la medida que entran dentro de sus proyectos e intereses. El vivo no tendrá profesión fija aunque su oficio específico será la política (Venturelli, 2010, p. 13-14).

Venturelli (2010) quien analiza críticamente la obra de Mafud, señala que muchas de las afirmaciones que hacen los argentinos sobre sí mismos, sin saberlo, vienen de las verdades establecidas en ese libro y que pasaron a formar parte del sentido común argentino al establecer juicios valorativos sobre su forma de ser "como uno de los discursos que fueron construyendo esa lógica que se transforma en sentido común a partir de ciertos modos de problematización de la argentinidad y se estructura como un régimen de verdad" (pág. 1). 
Hemos visto que el mismo concepto de cultura tiene múltiples acepciones, y para los propósitos de estas reflexiones, hemos adoptado el de Ruth Benedict. Según ella, la cultura es un patrón de características de personalidad que existe en un lugar específico. Hay en este enfoque la idea de una personalidad modal, que recoge el aire de familia, o las características del grupo en general sin que todos los miembros de la sociedad necesariamente las exhiban. En el caso de Venezuela, esta personalidad modal ha sido reconocida -o cuestionada- como el "pícaro" por los autores que hemos revisado. La orientación teórica de Benedict es a-temporal, pero hemos intentado buscar razones y causas históricas para contextualizar la aparición de esta idiosincrasia.

El pícaro aparece en variadas leyendas y es enseñado como un personaje divertido en libros para niños con el nombre de Tío Conejo. El tío Conejo es una especie de espejo literario, ocurrente y chispeante, en donde los lectores pueden mirar un patrón en el cual muchos participan, pero al mismo tiempo ha dado motivo a autores como Axel Capriles o Alejandro Moreno, Samuel Hurtado y José Luis Vethencourt para especular sobre las deficiencias del modelo o la configuración de la familia que lo produce. Escondido entre los valores libertarios del pícaro, algunos de ellos encuentran inconstancia, irresponsabilidad y una inquietante tendencia a seguir líderes autoritarios.

El pícaro es un sobreviviente. Ha sobrevivido la esclavitud, la cruenta guerra de independencia, los años de las sublevaciones constantes del siglo XIX, la penuria económica, sendas dictaduras políticas y un ambiente de crianza precaria, y lo ha hecho manteniendo intacto su sentido de humor. Tío Conejo, su encarnación en la literatura infantil, es gracioso, capaz de superar cualquier dificultad y siempre triunfa. 
En Venezuela, esta actitud tiene otro matiz, muy poco explorado dentro la configuración libertaria del pícaro: es la gran aceptación que se tiene en Venezuela de los demás en términos de las distinciones de raza ${ }^{7}$, etnias y lugares de origen, debido a: 1) la notable movilidad social que produjo la democracia con el impulso a la educación en todos sus niveles, durante los años del boom petrolero del siglo XX, donde familias de modestos recursos o de medios rurales o de escasa educación formal, pudieron enviar a sus hijos a la universidad (Romero, A, 2013) y 2) a que haya sido un país tradicionalmente receptor durante el siglo XX de grandes corrientes migratorias desde América Latina y Europa, por razones políticas y económicas (Valero, 2018), desde donde se generó un crisol de culturas. Por eso, a pesar de la desigualdad económica progresiva de los últimos quinquenios, permanece un espíritu de inclusión, que es un logro social de enorme importancia.

Pero el pícaro es autodestructivo. Hemos revisado sus dificultades para formar soluciones duraderas para sus problemas, como, por ejemplo, crear un sistema democrático de gobierno, o perseverar en el logro de metas a largo plazo, o establecer relaciones íntimas satisfactorias y perdurables.

El psicoanálisis nos dice que lo que no se examine queda latente y sedicioso en el inconsciente. En estas reflexiones hemos intentado arrojar algo de luz sobre este inconsciente caribeño que requiere una introspección colectiva.

\footnotetext{
7. Dice Pollak-Eltz (2021): “Mi tesis fundamental acerca del racismo en Venezuela dice así: Falta una conciencia racial y por tal motivo no hay discriminación racial abierta. No cabe duda de que bajo la superficie sí hay prejuicios hacia minorías de piel oscura, pero sólo saltan a la vista en ciertas situaciones sociales bien determinadas y nunca son expresadas abiertamente. En la "lucha de clases" los políticos nunca se sirven de "armas" raciales y no hay conflictos raciales. En el curso del tiempo, el segmento negro de la población se ha integrado en la sociedad multiétnico de nuestro país. No existen castas raciales, fracciones políticas de "gente de color" o instituciones sociales propios de los negros". Sin embargo, ... Se encuentra un mayor número de características raciales negroides en la clase baja, mientras, entre que en la clase "mantuana" predomina la piel blanca.... El hecho que desde 1854, año de la abolición de la esclavitud, no aparecen datos acerca de raza en los censos nacionales, ha contribuido a la ausencia de conciencia racial" (p. 272-273). Esto último es válido hasta el censo de 2011, año en el que el Instituto Nacional de Estadística introdujo en el censo una pregunta sobre la autopercepción racial por rasgos físicos, ascendencia familiar, cultura y tradiciones, con las alternativas de respuesta negro/a, afrodescendiente, morena/moreno, blanca/blanco, otra, ¿cuál?
} 


\section{BIBLIOGRAFÍA}

Aveledo, R. (1996). Seis preguntas sobre los venezolanos. En Zapata, R. (Ed.) Valores del Venezolano pp. 197-202. R. Caracas: Conciencia 21.

Benedict, R. (1934). Patterns of culture. Boston: Houghton Mifflin.

Boas, F. (1934). Introducción. En Benedict R., Patterns of culture, Boston Massachusetts: Houghton Mifflin p. xv-xvii.

Cabrujas, J. I. (1995a). La viveza Criolla, Destreza, mínimo esfuerzo o sentido del humor, Conferencia dictada el 12 de enero de 1995 en el ciclo La cultura del trabajo, organizado por la Fundación Sivensa en el Ateneo de Caracas, Venezuela, entre setiembre de 1994 y abril de 1995.

Cabrujas, J.I. (1995b/2012) El estado del disimulo. En José Ignacio Cabrujas habla y escribe. Caracas: Equinoccio. Recuperado de: http://prodavinci. com/2012/04/04/actualidad/el-estado-del-disimulo-cabrujas-entrevistado-por-luis-garcia-mora-y-ramon-hernandez/?output=pdf

Campbell, J. (1959/1965). The masks of God: Primitive mythology. Nueva York: The Viking.

Campbell, J. (1959/1991). Las máscaras de Dios. Mitología Primitiva. Madrid: Alianza.

Capriles, A. (1996). Antropología económica del igualitarismo. Montalbán (29). Caracas: UCAB, 159-172.

Capriles, A. (2008). La picardía del venezolano o el triunfo de Tío Conejo. Caracas: Taurus. 
Cole, N. (2019). The concept of collective consciousness. What it is and how it holds society together. Recuperado de: https://www.thoughtco.com/ collective-consciousness-definition-3026118

Cronick, K. (2018). El agarre del héroe. Saber UCV. Recuperado de: http://saber.ucv.ve/handle/123456789/17950

Durkheim, E. (1893). The Division of Labour in Society, G. Simpson (Trad.) Recuperado de: https://archive.org/stream/in.ernet.dli.2015.126617/2015.126617. The-Division-Of-Labour-In-Society_djvu.txt

Figueroa Brito, F. (1967). La población y la estructura social de Venezuela en las primeras décadas del siglo XIX. Bulletin hispanique 69 (3-4) 347-364. Recuperado de: https://www.persee.fr/doc/hispa_0007-4640_1967_ num_69_3_3909

Gruson, A. (2004). Cultura e identidad, Contribución introductoria al Simposio Cultura, migración e identidad. UCV \& Goethe Institut, Caracas, 7-8 de marzo de 2004.

Harris, J.Ch. (2007). Uncle Remus and Brear Rabbit. Project Gutenberg. [EBook \#22282]. Recuperado de: http://www.gutenberg.org/cache/ epub/22282/pg22282.txt

Hurtado, S. (2014). Comunidad y estructuras de acogida: Machismo, familismo anómico, fiesta y convivencia. La Representación del otro y la construcción de comunidad. En C. Delgado-Flores (Ed.) El Nosotros Venezolano. Comunicación y Democracia (pp. 31-47). Caracas: UCAB. 
Instituto Nacional de Estadística (2021). Censos de población y vivienda. Recuperado de: http://www.ine.gov.ve/documentos/Demografia/CensodePoblacionyVivienda/pdf/Cuestionario_Censo_2011.pdf

Lezama, H. (s/f). Tío Conejo: Raíces africanas y versiones venezolanas (Parte II). Recuperado de: https://steemit.com/spanish/@hlezama/tio-conejo-raices-africanas-y-versiones-venezolanas-parte-ii

Lodo-Platone, M.L. (2002). Familia y comunidad: organización social y patrones de interacción. En Platone, M.L. (Comp.). Familia e interacción social (pp. 25-49). Caracas: CEP/FHE.

Martínez-Monteagudo MC, Estévez E, Inglés C. (2013). Diversidad familiar y ajuste psicosocial en la sociedad actual Psicologia.com 17 (6). Recuperado de: http://hdl.handle.net/10401/6171

McClelland, D. (1976). Informe sobre el perfil motivacional observado en Venezuela. Caracas: Fundase.

McClelland, D. (1989). Estudio de la motivación humana. Narcea: Madrid.

Menand, L. (26 de Agosto de 2019). How cultural anthropologists redefined humanity. The New Yorker. Recuperado de: https://www.newyorker.com/magazine/2019/08/26/how-cultural-anthropologists-redefined-humanity

Moreno, A. (2008a). De la matrisocialidad a la matrirrelacionalidad. En: ¿Padre y Madre? Seis Estudios Sobre la Familia Venezolana. CIP. Convivium Minor (3) 91-109.

Moreno, A. (2008b). La Familia: aportes desde la antropología. En: Seis Estudios Sobre la Familia Venezolana. CIP. Convivium Minor (3) 73-90. 
Moreno, A. (2008c). ¿Padre y madre? En: Seis Estudios Sobre la Familia Venezolana. CIP. Convivium Minor (3) 59-71.

Moscovici, S. (1961/1979). El psicoanálisis, su imagen y su público. Buenos Aires: Huemul.

Piñango, R. (1996). Para comprender al venezolano de los noventa. En: Zapata, R. (Ed.) Los valores del venezolano (pp. 202-207). Caracas: Conciencia 21

Pollak-Eltz, A. (1993). ¿Hay o no hay racismo en Venezuela? Ibero-amerikanisches Archiv, 19 (3/4), Neue Folge, 271-289. Recuperado de: http:// www.jstor.org/stable/43392672

Real Academia Española (2020). Diccionario de la lengua española. Edición Tricentenario. Recuperado de: https://dle.rae.es/cultura

Restrepo, E. (2016). Escuelas clásicas del pensamiento antropológico. Perú: Meta Color. Recuperado de: https://www.researchgate.net/publication/331134973_Escuelas_Clasicas_del_Pensamiento_Antropologico

Rodríguez-Bello, L. y Rodríguez, I, (2006). El mito del tramposo en el "El Conuco de Tío Conejo" de Arturo Uslar Pietri. Tópicos de Cultura. América Latina y el Caribe I. Recuperado de: https://www.researchgate.net/ publication/268075993_EL_MITO_DEL_TRAMPOSO_EN_EL_EL_CONUCO_DE_TIO_CONEJO_DE_ARTURO_USLAR_PIETRI

Rodríguez, M. F. (2010). Tío Conejo celebra. La picardía criolla se anuncia a 'viva voz'. [Entrevista a Axel Capriles, psicólogo venezolano. Entrevista realizada el 17 de junio de 2009.]. Anuario Electrónico de Estudios en Comunicación Social "Disertaciones" 3 (1) Recuperado de: http://erevistas. saber.ula.ve/index.php/Disertaciones/ 
Romero G., O. (1999). Crecimiento Psicológico y Motivaciones Sociales. Mérida: Rogya.

Romero S, A. (2006). El ascensor detenido. La crisis de la movilidad social a través de la titulación. Espacio Abierto, 15 (1-2). Recuperado de: https:// produccioncientificaluz.org/index.php/espacio/article/view/2154

Salamanca, L. (2015). Las tres etapas más violentas en la historia de Venezuela. PolítiKa UCAB. Recuperado de: https://politikaucab.net/2015/06/12/ las-tres-etapas-mas-violentas-en-la-historia-de-venezuela/

Torres, A. (2009). La herencia de la tribu. El mito de la independencia a la revolución Bolivariana. Caracas: Alfa.

Uslar Pietri, A. (1931). Lanzas coloradas. Caracas: Zeus.

Uslar Pietri, A. (1987). El conuco de Tío Conejo. Zaragoza: Edelvives.

UCAB/ENCOVI (2020). Encuesta Nacional de Condiciones de Vida 2019 2020.: Recuperado de: https://www.proyectoencovi.com/informe-interactivo-2019

UNESCO (2001). Declaración Universal de la UNESCO sobre la Diversidad Cultural. Recuperado de: http://portal.unesco.org/es/ev.php-URL_ ID=13179\&URL_DO=DO_TOPIC\&URL_SECTION=201.html

Valero, M. (2018). Venezuela, migraciones y territorios fronterizos. Línea Imaginaria. 6 (3). Recuperado de: http://revistas.upel.digital/index.php/linea_imaginaria/article/view/7449/4258 
Venturelli, C. V. (2010). Julio Mafud: El sociólogo del sentido común de la argentinidad. VI Jornadas de Sociología de la UNLP, 9 y 10 de diciembre de 2010, La Plata, Argentina. En Memoria Académica. Recuperado de: http://www.memoria.fahce.unlp.edu.ar/trab_eventos/ev.5031/ ev.5031.pdf

Vethencourt, J.L. (1974). La estructura familiar atípica y el fracaso histórico cultural en Venezuela. SIC (362). Recuperado de: http://gumilla.org/ biblioteca/bases/biblo/texto/SIC1974362_67-69.pdf

Zapata, R. (1996). Los valores del venezolano. Caracas: Conciencia 21. 